\title{
Look, here comes the library van! Optimising the timetable of the mobile library service on the Isle of Wight
}

\author{
Tanutr Rienthong ${ }^{1}$, Andrew Walker ${ }^{2}$, Tolga Bektaş ${ }^{1^{\star}}$ \\ ${ }^{1}$ School of Management and Centre for Operational Research, Management Science and \\ Information Systems (CORMSIS), University of Southampton, Highfield, Southampton, SO17 1BJ \\ ${ }^{2}$ Isle of Wight Council, Library HQ, 5 Mariners Way, Cowes, Isle of Wight PO31 8DP
}

\begin{abstract}
This paper describes an approach taken to optimise the timetable of the mobile library service operating on the Isle of Wight. The mobile library visits over 90 communities on the island, offering books, DVDs, videos and CDs and operates on a periodic timetable. The optimisation problem is formulated as a multiple travelling salesmen model with additional time-balancing constraints on route durations. The paper also shows ways in which data required for the model, in particular travel times, was gathered and discusses practical issues arising in preprocessing the data to fit the purposes of the case study. The model is used to produce an improved timetable over the current one that implies driving time reductions of up to $25 \%$ and yields routes that are better balanced in terms of time spent on the visits made each day. The model is also used to test various scenarios differing with respect to the number of locations visited and days over which the service operates.
\end{abstract}

Keywords. multiple travelling salesman problem; routing; integer programming; optimisation.

${ }^{*}$ Corresponding author.

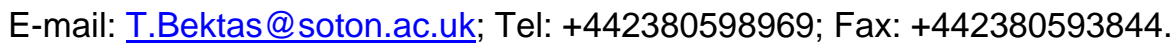




\section{Introduction}

The Isle of Wight Council's Library Service serves a population of around 140,000, and amongst unitary authorities is in the top quartile for visits and issues. The service has a stock of just under a quarter of a million books and issues close to one million books, CDs, DVDs and videos every year. There are currently 28,000 active borrowers out of a population of 140,000 but the service is also used for its internet-based services, access to other council services, and for a wide variety of enquiries.

The Isle of Wight Council's Library Services has 11 branches providing service for Bembridge, Brighstone, Cowes, East Cowes, Freshwater, Newport, Niton, Ryde, Sandown, Shanklin, and Ventnor. The main library is the Lord Louis Library located in Newport. Figure 1 shows a map of the Isle of Wight and the main centres of population on the island. The Council also provides additional library services, namely the Mobile Library Service which visits locations on the island where there are no static libraries, and the Home Library Service which delivers to the homes of people who are unable to visit their local library due to being housebound. In addition, they also have a delivery van in order to provide facilities for library branches, pre-school, mid-school and services for each of the island's three prisons.

The mobile library service offers services to locations where there are no libraries. The mobile service operates on a three-week timetable. Over weeks one and two, communities in towns, villages and rural areas are visited. In week three, it provides service to shelter housing residents. The mobile library currently serves 98 locations over a three-week period consisting of 38 locations in week one, 42 locations in week two and 18 locations in week three. Over the three weeks, the mobile library spends around 93 hours and makes about 282.5 miles in travelling around the island. This time is a combination of driving and service times. 


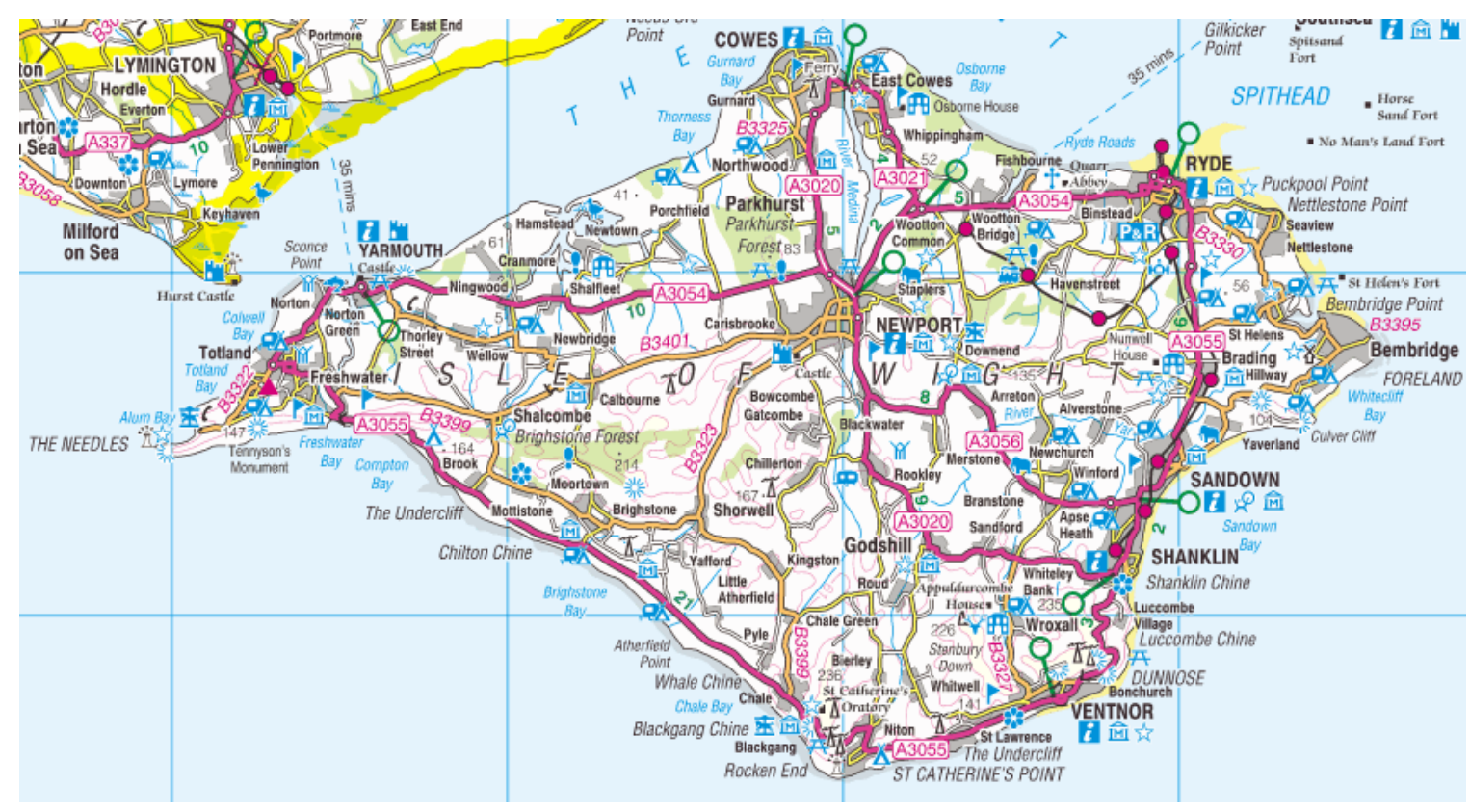

Figure 1: A map of the Isle of Wight

(Contains Ordnance Survey data @ Crown copyright and database rights 2010)

The Isle of Wight Library Service is currently undertaking a review of their mobile and home library service provision in terms of route revision, vehicle suitability, service provision and staffing. The aim of the review is to maintain the delivery of the high-quality service to customers, but at a significantly reduced cost.

The main objective of this paper is to develop alternative timetables for the Mobile Library to improve and enhance the service on the Isle of Wight in terms of both the total mileage and the time spent on the routes. Through the use of mathematical modelling and optimisation, this paper will first show how the current schedule can be improved. The model will also be used to generate alternative timetables with differing characteristics. The paper will describe how travel time data required as an input to the proposed model was collected and will discuss some practical issues arising in pre-processing the data to fit to the needs of the case study. More specifically, we will show that travel times as estimated through an online map database needed to be modified before being used in the model. The next section describes the modelling and optimisation approach for the problem and discusses the requirements for data collection and processing. 


\section{Modelling and optimisation}

The first part of this section provides a detailed description of the current practice and discusses data requirements. The second part presents a formal definition of the problem and describes the model used to produce the new timetables.

\subsection{Description of the current practice and data collection}

The mobile library service visits 98 locations on the island over a time horizon of 16 days, and this timetable is repeated throughout the year. Tours start daily from the Library HeadQuarters (HQ) located in Cowes and return to the same location at the end of each day. To give the reader an idea of the existing timetable in place, we first present some detailed statistics in Table 1 as to the total distance traversed by the mobile library, as well as the associated travel and service times for each day.

Table 1. Summary statistics for the timetable in use

\begin{tabular}{|c|c|c|c|c|c|}
\hline & Day & $\begin{array}{c}\text { Distance } \\
\text { (miles) }\end{array}$ & $\begin{array}{l}\text { Scheduled } \\
\text { travel time } \\
\text { (minutes) }\end{array}$ & $\begin{array}{l}\text { Service } \\
\text { time }\end{array}$ & $\begin{array}{l}\text { Total } \\
\text { Time }\end{array}$ \\
\hline \multirow{6}{*}{ Week 1} & Monday & 26.0 & $2: 45$ & $2: 25$ & $5: 10$ \\
\hline & Tuesday & 12.5 & 1:55 & $4: 45$ & $6: 40$ \\
\hline & Wednesday & 17.1 & $2: 30$ & $2: 30$ & $5: 00$ \\
\hline & Thursday & 20.6 & 3:00 & $4: 25$ & $7: 25$ \\
\hline & Friday & 16.6 & $2: 00$ & $4: 20$ & $6: 20$ \\
\hline & Saturday & 12.6 & $0: 45$ & 4:00 & $4: 45$ \\
\hline \multirow{6}{*}{ Week 2} & Monday & 25.4 & $2: 50$ & $2: 40$ & $5: 30$ \\
\hline & Tuesday & 25.6 & $2: 40$ & 3:15 & $5: 55$ \\
\hline & Wednesday & 19.9 & $2: 20$ & $2: 55$ & $5: 15$ \\
\hline & Thursday & 9.00 & $2: 10$ & $3: 40$ & $5: 50$ \\
\hline & Friday & 20.1 & $2: 40$ & $4: 30$ & $7: 10$ \\
\hline & Saturday & 7.3 & 0:20 & 4:00 & $4: 20$ \\
\hline \multirow{6}{*}{ Week 3} & Monday & \multicolumn{4}{|c|}{ Off-road (Admin day) } \\
\hline & Tuesday & 28.5 & $2: 55$ & $3: 35$ & $6: 30$ \\
\hline & Wednesday & 8.9 & $2: 15$ & 4:00 & $6: 15$ \\
\hline & Thursday & 13.8 & $2: 10$ & $3: 30$ & $5: 40$ \\
\hline & Friday & 18.3 & $2: 15$ & $3: 00$ & $5: 15$ \\
\hline & Total & 282.5 & $35: 30$ & & 93:00 \\
\hline
\end{tabular}


The service time for each location is dependent on its population. This data is extracted from the current schedule and a summary is presented in Figure 2.

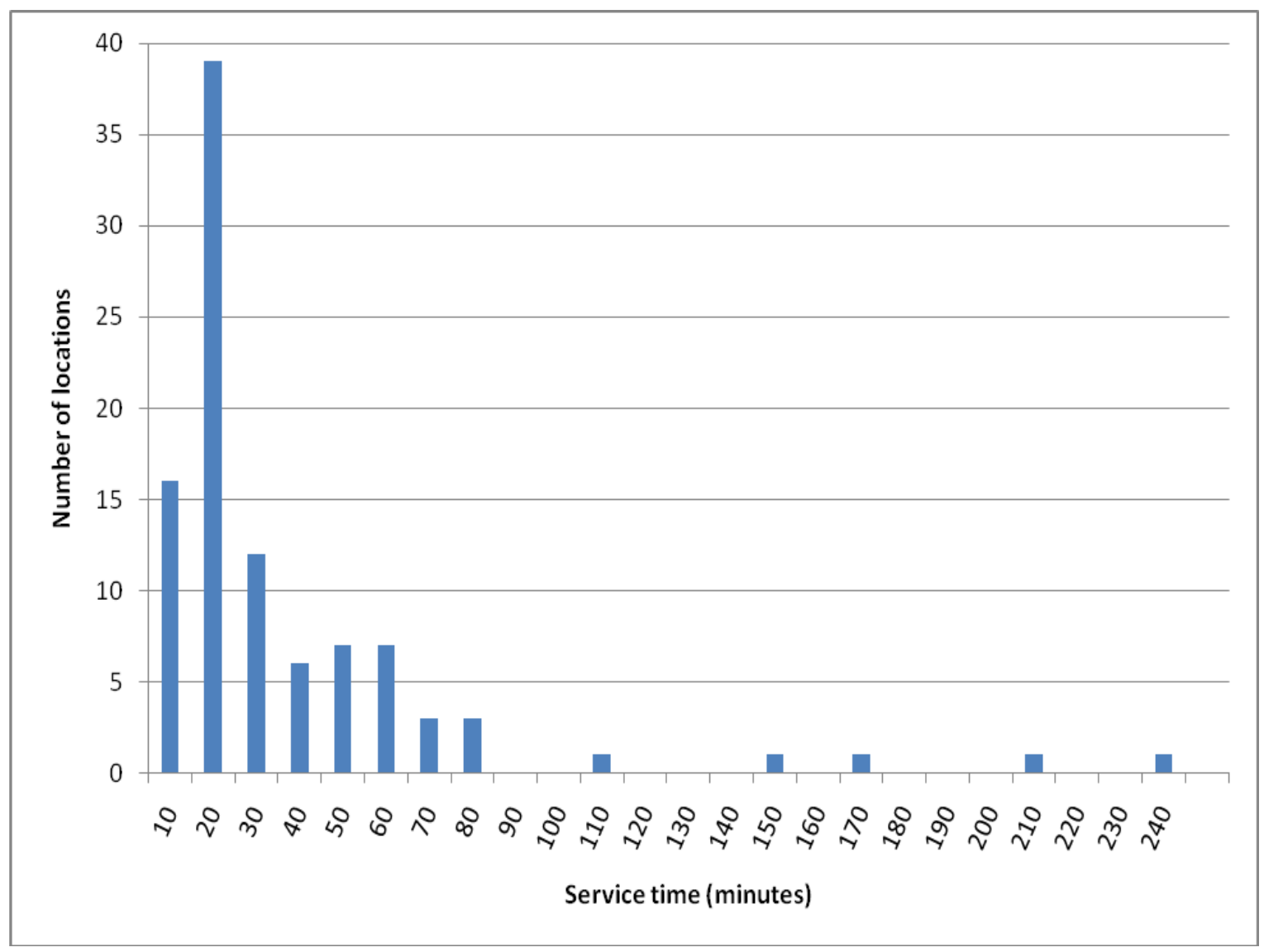

Figure 2. Histogram showing the spread of the service times for the 98 locations

As Figure 2 shows, there are 16 locations with service times of up to 10 minutes and 39 locations with service time of around 20 minutes. Of the remaining locations, there are 38 with service times ranging between 30 and 80 minutes. Finally, only four of the locations visited have service times higher than 100 minutes with the maximum being 4 hours (240 minutes).

There are two fundamental sets of data required for this study: (i) driving times between every pair of locations, and (ii) location durations (service times) at each location visited. The latter was readily available from the existing timetable as is as shown in Figure 2. The former set was collected using an online map database 
(Google Maps, 2010). This meant that $\left(99^{2}-99\right) / 2=4851$ individual distances were manually entered and the corresponding estimated driving times were extracted using the postcodes available to us, yielding a $99 \times 99$ travel time matrix. However, when these driving times given by the online database were compared with those available in the schedule, some discrepancies were found. Table 2 shows these discrepancies in greater detail for a section of a particular route.

Table 2. Discrepancies between the collected data and the existing schedule

\begin{tabular}{cccc}
\hline & Location & \multicolumn{2}{c}{ Driving time from the previous location } \\
\cline { 2 - 4 } Week 1 Friday & Library HQ & $\begin{array}{c}\text { Data from the } \\
\text { online map }\end{array}$ & $\begin{array}{c}\text { Data from the actual } \\
\text { schedule }\end{array}$ \\
\hline PO31 8PD & Shorwell & - & - \\
PO30 3JT & Limerstone & $0: 21$ & $0: 30$ \\
PO30 4AA & Yafford & $0: 03$ & $0: 05$ \\
PO30 3LH & Hulverstone & $0: 02$ & $0: 05$ \\
PO30 4EH & Brook & $0: 08$ & $0: 20$ \\
PO30 4LD & Calbourne & $0: 01$ & $0: 05$ \\
PO30 4JD & Kinchington Rd & $0: 08$ & $0: 20$ \\
PO30 5ST & Marlborough Rd & $0: 10$ & $1: 20^{\star}$ \\
PO30 5RQ & $0: 01$ & $0: 05$ \\
\hline
\end{tabular}

*includes one-hour lunch break

A closer look at the above-mentioned discrepancy revealed that the mobile library bus was driving slower than an average car, due to its size, and hence required higher travel times. The figures presented in Table 1 as well as the rest of the timetable indicated that the scheduled travel times were about twice as much as the estimations given through the online database. To reflect this difference, we have multiplied all elements of the $99 \times 99$ driving time matrix by two and used this revised data set in the computations. We note that the modification performed on the data set will not affect the resulting tours since all elements are magnified by the same amount. However, the modification yields a better estimation of the actual times spent travelling and therefore will have an impact on the resulting schedules and the way in which they would be implemented. 
A tabulated summary of the current timetable in terms of driving and service times is given in Table 3. In this table, we present statistics for the total driving time with respect to two sources; one is based on the data collected through the online database, and other based on the actual schedule of the mobile library service. These figures are presented under columns two and three in Table 3. The total service time remains constant for each location for which there is only one set of statistics, and these are presented in the last column of Table 3.

Table 3: An overall summary of the current time table

\begin{tabular}{lccc}
\hline & $\begin{array}{c}\text { Total driving time } \\
\text { based on online map } \\
\text { data }\end{array}$ & $\begin{array}{c}\text { Total driving time } \\
\text { based on the actual } \\
\text { schedule }\end{array}$ & Total service time \\
\hline Week 1 (6 days) & $13: 38$ & $12: 55$ & $22: 25$ \\
Week 2 (6 days) & $10: 43$ & $13: 00$ & $21: 00$ \\
Week 3 (4 days) & $8: 20$ & $9: 35$ & $14: 05$ \\
\hline Total (16 days) & $\mathbf{3 2 : 3 1}$ & $\mathbf{3 5 : 3 0}$ & $\mathbf{5 7 : 3 0}$ \\
\hline
\end{tabular}

\subsection{Formal definition of the problem and the optimisation model}

The problem of finding an optimal timetable for the mobile library service corresponds to distributing the set of 98 locations to be visited over three weeks. The first two weeks are of 12 days long including Saturdays but not Sundays, whereas the third week is only of four days long. The problem also involves finding, for each day, the order in which the locations will be visited. In other words, the problem involves finding the optimal routes to traverse in each day. An additional aspect of the problem involves balancing the total time spent in each day by the service, including the travel time from one location to another and service time at each location.

Routing problems have long been studied in the literature. The Traveling Salesman Problem (TSP) is a well-known member of this class of problems which consists of finding a lowest-cost tour among a set of cities such that each city is visited exactly once and the tour starts from and ends at a so-called "depot" or a 
"home" node (see Laporte, 1992, 2010 for overviews). In our study, the routing problem of the mobile library is modelled using an extension of the TSP named as the multiple Travelling Salesman Problem (mTSP). The mTSP consists of finding routes for $m$ salesmen who all depart from and return to a depot such that each city is visited exactly once and that the total length of the $m$ tours formed is minimised. There are several variations of the mTSP, ranging from those with single to multiple depots, and those with additional restrictions such as bounds on the number of cities visited (Bektaş, 2006).

In our context, each of the $m$ tours in the mTSP corresponds to one of the 16 days to be planned for and each tour itself will yield the order of the locations in a tour to be visited on the corresponding day.

The model used in this study is in the form of a 0-1 mixed integer linear programming formulation. We denote the number of locations by $n$ and the number of days to plan for by $m$. The set $N=\{1,2, \ldots, n\}$ is the index set of all locations (or nodes) to be visited in which "home" (i.e., Library HQ) is represented by node 1 . The remaining indices correspond to the 98 locations to be visited. $C_{i j}$ represents the driving time from location $i$ to location $j(i \neq j)$ in minutes. The service time spent in a given location $i \in N$ is represented by $S_{i}$. The total time spent on a tour is composed of the driving time and service times spent at each of the locations. As for the balancing aspect of the problem, an upper bound of $T$ minutes is imposed on the total time spent by the mobile library service on each day. Similarly, it is required that the service spends at least a lower bound of $L$ minutes every day. Under this definition, the more the values of $L$ and $T$ approach one another, the more balanced the resulting tours will be.

The proposed model makes use of a binary variable $X_{i j}$ which takes the value 1 if the service travels from location $i \in N$ to location $j \in N$, and 0 otherwise. An additional (continuous) variable $V_{i}$ is defined to represent the arrival time of the service at node $i \in N$. The model is presented below. 


$$
\begin{aligned}
& \text { Minimise } \quad \sum_{i=1}^{n} \sum_{j=1}^{n} C_{i j} X_{i j} \\
& \text { subject to } \quad \sum_{j=2}^{n} X_{1 j}=m \text {, } \\
& \sum_{j=2}^{n} X_{j 1}=m, \\
& \sum_{i=1}^{n} X_{i j}=1 \\
& j=2, \ldots, n, \\
& \sum_{j=1}^{n} X_{i j}=1 \quad i=2, \ldots, n, \\
& V_{i}-V_{j}+\left(T+C_{i j}+S_{i}\right) X_{i j}+\left(T-C_{i j}-S_{j}\right) X_{j i} \leq T \\
& i, j=2, \ldots, n ; i \neq j \text {, } \\
& V_{i}+\left(C_{i 1}+S_{i}\right) X_{i 1} \leq T \quad i=2, \ldots, n, \\
& V_{i}-\left(L-C_{i 1}-S_{i}\right) X_{i 1} \geq 0 \quad i=2, \ldots, n \text {, } \\
& V_{i}-C_{1 i} X_{1 i} \quad \geq 0 \quad i=2, \ldots, n \text {, } \\
& V_{i}-C_{1 i} X_{1 i}+T X_{1 i} \leq T \quad i=2, \ldots, n \text {, } \\
& X_{i j} \in\{0,1\} \quad i, j=2, \ldots, n ; i \neq j \text {. }
\end{aligned}
$$

In the model presented above, constraints (1) and (2) ensure that the timetable of the mobile library service covers $m$ days, with each tour starting and ending at the Library HQ (node 1). Constraints (3) and (4) ensure that each location appears exactly once in any tour, i.e., it is visited only once over the planning horizon of $m$ days. Constraints (5) are used to prevent subtours, which are tours that are formed within the locations not connected to Library HQ. These constraints also help to define the variables $V_{i}$ in such a way that if the service visits location $j$ immediately after visiting location $i$, then the arrival time in location $j$ will be equal to the arrival time in location $i$ added to the service time in location $i$ and the travel 
time between these two nodes. Constraint (6), (7), (8) and (9) are used to guarantee that the total time spent on each tour is between $L$ and $T$ minutes.

The above model is an extension of the standard mTSP model found in the literature (see, e.g., Kara and Bektaş, 2006). As far as we are aware, constraints (6), (7), (8) and (9) used to balance the routes in terms of travel time are the novel features of this model.

\section{Results}

It is well known that routing problems are difficult to solve optimally and that heuristics offer reasonably good solutions within relatively short computation times (see, e.g., Salhi and Currie, 2009). However, it is not the intention of this paper to describe a new solution method for the model but rather to make use of the proposed model in obtaining solutions that improve upon the current practice. To this end, we used GUROBI version 3.0.1 (Gurobi Optimization, 2010), a state-ofthe-art optimiser for solving the proposed model. All experiments were conducted on a $2.4 \mathrm{GHz}$ MacBook.

The model (1)-(10) was coded using the parameters of the current timetable and run on a pre-defined set of scenarios generated in consultation with the Isle of Wight Library $\mathrm{HQ}$ in line with their review. Further details on the scenarios generated and the associated results are given below.

\section{Scenario 1}

This scenario is based on the current timetable with $n=99$ locations (including the Library HQ) and $m=16$ service days covering three weeks. After consultation with the mobile library service driver and Library Services, and in line with the current timetable, it was decided to set $L$ and $T$ equal to 4 hours (240 minutes) and 6.30 hours (390 minutes), respectively, for this scenario. The optimiser for the 
corresponding model was run for over 10 hours and a summary of the resulting solution is shown in Table 4.

Table 4. Summary statistics for the new timetable produced under Scenario 1

\begin{tabular}{|c|c|c|c|c|}
\hline & Day & $\begin{array}{l}\text { Scheduled travel time } \\
\text { (minutes) }\end{array}$ & $\begin{array}{l}\text { Service } \\
\text { time }\end{array}$ & Total Time \\
\hline \multirow{6}{*}{ Week 1} & Monday & $2: 08$ & $3: 15$ & $5: 23$ \\
\hline & Tuesday & $2: 08$ & 4:00 & $6: 08$ \\
\hline & Wednesday & $1: 23$ & $2: 45$ & 4:08 \\
\hline & Thursday & $1: 12$ & $4: 20$ & $5: 32$ \\
\hline & Friday & $1: 30$ & $2: 50$ & $4: 20$ \\
\hline & Saturday & $1: 46$ & 3:00 & $4: 46$ \\
\hline \multirow{6}{*}{ Week 2} & Monday & $2: 15$ & $3: 45$ & $6: 00$ \\
\hline & Tuesday & $0: 28$ & $3: 45$ & $4: 13$ \\
\hline & Wednesday & $2: 08$ & $3: 20$ & $5: 28$ \\
\hline & Thursday & $1: 40$ & $4: 50$ & $6: 30$ \\
\hline & Friday & $1: 36$ & $3: 20$ & $4: 56$ \\
\hline & Saturday & $2: 18$ & 4:00 & $6: 18$ \\
\hline \multirow{6}{*}{ Week 3} & Monday & \multicolumn{2}{|c|}{ Off-road (Admin day) } & \\
\hline & Tuesday & $1: 48$ & 4:10 & $5: 58$ \\
\hline & Wednesday & $1: 00$ & 3:05 & 4:05 \\
\hline & Thursday & $2: 13$ & 4:05 & $6: 18$ \\
\hline & Friday & 1:06 & 3:00 & $4: 06$ \\
\hline & Total & 26:39 & & 84:09 \\
\hline
\end{tabular}

As can be seen from Table 4, the new timetable produced through the proposed model results in a total driving time of 26 hours and 39 minutes and this is an improvement of 8 hours and 51 minutes over the current timetable, translating into a time saving of around $24.93 \%$. If the comparisons are made on the basis of data obtained from the online map, then the corresponding time reduction is 5 hours and 52 minutes.

\section{Scenario 2}

Scenario 2 will look at the case where mobile library locations within a two-mile radius of the main libraries Newport, Ryde, Cowes, Freshwater, Sandown and Ventnor are not included in the model. The assumption here is that these locations 
would be served by the respective main libraries, rather than by the mobile library. Without such locations, the number of locations reduces to $n=72$. Given the reduced number of locations, we run the model for two cases with $m=16$ and $m=$ 12 days respectively, where the latter corresponds to two weeks. The reason for testing the $m=12$ case is due to the decreased number of locations to be visited. For this scenario, it was decided to increase $L$ to 5 hours (300 minutes) but keep $T$ same at 6.30 hours (390 minutes).

For the case with $m=16$ days, the optimisation engine was run for around 23 hours on the model. We present a summary of the resulting solution in Table 5.

Table 5: The summary table for Scenario 2 with $m=16$

\begin{tabular}{lcccc}
\hline & $\begin{array}{c}\text { Total driving } \\
\text { time }\end{array}$ & Time savings & $\begin{array}{c}\text { Total service } \\
\text { time* }^{*}\end{array}$ & Time savings \\
\hline $\begin{array}{l}\text { current time table } \\
\text { based on actual }\end{array}$ & $35: 30$ & $-5: 04$ & $57: 30$ & $18: 45$ \\
$\begin{array}{l}\text { schedule } \\
\text { current time table } \\
\text { based on online data }\end{array}$ & $32: 31$ & $-8: 03$ & $57: 30$ & $18: 45$ \\
$\begin{array}{l}\text { Scenario 2 (16 days) } \\
\text { Scenarion }\end{array}$ & $40: 34$ & - & $36: 45$ & - \\
\hline
\end{tabular}

* Service times do not include lunch breaks

Table 5 shows a comparison between the current timetable and the new one with 72 locations and 16 days. It is interesting to note that the total driving time in this scenario is longer than that of the current time table, with the reason being the locations that were removed lead to an increased distance between locations. However, the increase in the driving time is compensated by the reduction in total service time as shown in the last column of Table 5. When the changes in total driving and service times are combined, it can be seen that the new scenario results in a significant reduction of the overall time spent by the mobile library service for the 72 locations.

The second case of Scenario 2 is where the number of service days is reduced from 16 days to 12 days while all other parameters remain fixed. The optimisation 
in this case was run for 24 hours and a summary of the results are presented in Table 6.

Table 6: The summary table for Scenario 2 with $m=12$

\begin{tabular}{lcccc}
\hline & $\begin{array}{c}\text { Total driving } \\
\text { time }\end{array}$ & Time savings & $\begin{array}{c}\text { Total service } \\
\text { time* }^{*}\end{array}$ & Time savings \\
\hline $\begin{array}{l}\text { current time table } \\
\text { based on actual } \\
\text { schedule }\end{array}$ & $35: 30$ & $14: 08$ & $57: 30$ & $18: 45$ \\
\hline $\begin{array}{l}\text { current time table } \\
\text { based on online data }\end{array}$ & $32: 31$ & $11: 09$ & $57: 30$ & $18: 45$ \\
\hline Scenario 2 (12 days) & $21: 22$ & - & $36: 45$ & - \\
\hline
\end{tabular}

* Service times do not include lunch breaks

Table 6 shows that the total driving time is significantly lower than that of the current timetable when the services operates on a periodic timetable of 12 days, rather than 16 to serve the 72 locations. The savings in driving time combined with the reduction in the total service time shows that a two-week, rather than a threeweek long timetable results in much less time to be spent in driving and servicing the locations.

\section{Scenario 3}

This scenario aims to create a new timetable which will remove all locations within a two-mile radius of every main library on the Isle of Wight, namely Newport, Ryde, Cowes, Freshwater, Sandown, Ventnor, Bembridge, East Cowes, Shanklin, Brighstone and Niton. This implies a reduction in the total number of locations from 99 to 59, with 40 locations removed. The number of service days in this case is set equal to 12 days while all other parameters remain constant. The optimisation process for the model corresponding to Scenario 3 was run for around 2 hours. A summary of the results are presented in Table 7. 
Table 7: The summary table for scenario 2 with $m=12$

\begin{tabular}{lcccc}
\hline & $\begin{array}{c}\text { Total driving } \\
\text { time }\end{array}$ & Time savings & $\begin{array}{c}\text { Total service } \\
\text { time* }\end{array}$ & Time savings \\
\hline $\begin{array}{l}\text { current time table } \\
\text { based on actual } \\
\text { schedule }\end{array}$ & $35: 30$ & $8: 23$ & $57: 30$ & $26: 50$ \\
\hline $\begin{array}{l}\text { current time table } \\
\text { based on online data }\end{array}$ & $32: 31$ & $5: 24$ & $57: 30$ & $26: 50$ \\
\hline Scenario 3 & $27: 07$ & - & $30: 40$ & - \\
\hline
\end{tabular}

* Service times do not include lunch breaks

As can be seen from Table 7, the total driving time for Scenario 3 is around 27 hours which implies a reduction of 8 hours and 23 minutes over the current timetable based on the actual schedule and a reduction of 5 hours 24 minutes over the current timetable based on online data. Further reductions in the total service time can be seen in the last column of Table 7, which is due to the number of reduced locations.

\subsection{Summary and Comparisons}

An important aspect of the model proposed in this study is its feature of balancing the workload (as measured by the daily time spent by the service) over a number of days, in addition to minimising the total travel time of the mobile library service. Table 8 presents a general comparison between the current timetable and the three scenarios tested in terms of the total driving time. This table also presents, in the last row, the standard deviation (SD) for each scenario as well as that of the current timetable as an indicator of how "balanced" the new solutions are. 
Table 8: Summary table comparing the current timetable with three scenarios with regards to the driving time (in minutes)

\begin{tabular}{lccccc}
\hline & $\begin{array}{c}\text { Current } \\
\text { timetable }\end{array}$ & Scenario 1 & $\begin{array}{c}\text { Scenario 2 } \\
(\boldsymbol{m}=\mathbf{1 6})\end{array}$ & $\begin{array}{c}\text { Scenario 2 } \\
(\boldsymbol{m}=\mathbf{1 2})\end{array}$ & Scenario 3 \\
\hline Day 1 & 198 & 128 & 150 & 102 & 176 \\
Day 2 & 100 & 128 & 156 & 113 & 104 \\
Day 3 & 114 & 83 & 102 & 126 & 142 \\
Day 4 & 154 & 72 & 196 & 106 & 158 \\
Day 5 & 144 & 90 & 188 & 106 & 150 \\
Day 6 & 100 & 106 & 198 & 98 & 176 \\
Day 7 & 136 & 135 & 208 & 154 & 172 \\
Day 8 & 116 & 28 & 136 & 146 & 100 \\
Day 9 & 123 & 128 & 201 & 129 & 145 \\
Day 10 & 60 & 100 & 168 & 118 & 160 \\
Day 11 & 140 & 96 & 135 & 68 & 68 \\
Day 12 & 68 & 138 & 68 & 76 & 76 \\
Day 13 & 184 & 108 & 152 & - & - \\
Day 14 & 78 & 60 & 140 & - & - \\
Day 15 & 100 & 133 & 160 & - & - \\
Day 16 & 138 & 66 & 76 & - & - \\
\hline SD & $\mathbf{3 8 . 4 3}$ & $\mathbf{3 1 . 9 8}$ & $\mathbf{4 2 . 6 2}$ & $\mathbf{2 5 . 3 0}$ & $\mathbf{3 8 . 6 3}$ \\
\hline
\end{tabular}

The figures given in Table 8 clearly show that Scenario 1, which is an optimised version of the current timetable, produces a more balanced set of routes as indicated by the reduced standard deviation. The table also shows that, should Scenario 2 be adopted, then a 12-day time period results in a better balanced set of routes with an even smaller standard deviation than that of Scenario 1.

\section{Conclusions}

This paper described a practical routing problem that arises in producing a timetable for the mobile library service on the Isle of Wight. A mathematical model in the form of an integer programming formulation is proposed for the problem which not only minimises the total driving time spent by the service but also balances the time spent on the routes each day. The model can be generated easily and fed into an off-the-shelf optimiser to produce practical solutions. The model could easily be used by practitioners and is flexible enough to be adapted to their own needs. Using the proposed model, we were able to produce a new 
timetable for the mobile library service which not only reduced the driving time requirements of up to $25 \%$ but also helped to better balance the route durations by reducing the standard deviation of the set of routes by around $17 \%$. We also tested several scenarios looking at a reduced number of locations and days and investigated the impacts of these changes on the total driving and service time.

One (expected) challenge encountered in this research was the difficulty of solving the model to optimality. As mentioned in the previous section, the time to run the models for the four scenarios varied from two hours to 24 hours. The respective optimality gaps for Scenarios 1,2 (with $m=16$ ), 2 (with $m=12$ ) and 3 were $28.4 \%, 40.1 \%, 12.4 \%$ and $29.5 \%$, respectively, which shows the difficulty of obtaining optimal solutions within reasonable amount of computational time. The quoted statistics on the optimality gaps shows the need for theoretical developments in solving these types of problems to optimality in efficient and effective ways. This is especially the case for modelling and solving more complex library delivery operations (Apte and Mason, 2006). One observation we made in our experimentation is that the solution of the proposed model becomes much more difficult with increasing lower bound $L$ on the travel time. However, the produced solutions were good enough for practical purposes of this research and showed improvement over the current practice.

Acknowledgments. This research was based on a summer project organised jointly by the four MSc programmes run by the Centre of Operational Research, Management Science and Information Systems (CORMSIS) at the University of Southampton and carried out in collaboration with the Isle of Wight Council. At the time of completing this research, the first author was MSc student at the University of Southampton. The authors would like to thank Astrid Davies and Dr lan Rowley for helping to set up the project, and the Editor-in-Chief for his constructive comments on the article. 


\section{References}

Apte UM, Mason FM (2006). Analysis and improvement of delivery operations at the San Francisco Public Library. Journal of Operations Management 24: 325346.

Bektaş T (2006). The multiple traveling salesman problem: An overview of formulations and solution procedures. Omega 34: 209-219.

Google Maps (2010) Available at http://maps.google.co.uk/ (Accessed July 2010).

Gurobi Optimization (2010) Available at http: //www. gurobi.com/.

Kara I, Bektaş T (2006). Integer linear programming formulations of multiple salesman problems and its variations. European Journal of Operational Research 174: $1449-1458$.

Laporte G (1992). The traveling salesman problem: An overview of exact and approximate algorithms. European Journal of Operational Research 59: 231-247.

Laporte G (2010). A concise guide to the Traveling Salesman Problem. Journal of the Operational Research Society 61: 35-40.

Salhi S, Currie RH (2009). Heuristics are here to help your online vehicle scheduling. OR Insight 22: 88-104. 